\title{
Operating Analysis of DC and RF Characteristics of RF MEMS Capacitive Coupled Shunt Switches by Geometrical Modifications and Material Selection
}

\author{
E. S. Shajahan and M. S. Bhat
}

\begin{abstract}
This paper critically analyses the DC and RF performance of RF MEMS capacitive coupled switches with respect to changing beam geometry. Switches are designed for operation in the range 10-40 GHz. Pull-in analysis of the switch is performed with aluminum, gold, titanium and platinum as the membrane material. Simulation reveals that for the same geometry, actuation voltage of the switch with aluminum beam is $18.75 \mathrm{~V}$ and that with platinum beam is $27.1875 \mathrm{~V}$. RF analysis shows that insertion loss as low as $0.2 \mathrm{~dB}$ and isolation as high as $60 \mathrm{~dB}$ can be achieved by proper switch design. Design and DC analysis of the proposed switch is carried out using CoventorWare 2010 and RF performance by High frequency Structure simulator (Ansoft HFSS) v 13.0
\end{abstract}

Index Terms-RF MEMS, spring constant, Young's Modulus, Poisson's ratio.

\section{INTRODUCTION}

Recent research has established beyond doubt that RF MEM (Radio Frequency Micro Electro Mechanical) switches will play a significant role in communication systems in the near future. This is because of the numerous advantages RF MEMS switches have over their semiconductor counterparts (PIN and FET switches) in terms of their low power dissipation, transmission loss, high quality factor, better isolation and very low intermodulation products [1].

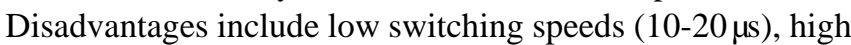
actuation voltages $(15-60 \mathrm{~V})$ and hot switching in high power applications and failure due to stiction phenomenon. Stiction is due to capillary adhesion, dielectric charging, and contact adhesion. The stiction problem is predominant with small gaps, low stiffness and smooth surfaces [1]. Despite better performance over other competing technologies such as PIN or FET switches, reliability issues hamper commercialization of RF MEM capacitive switches.

The capacitive coupled RF MEM shunt switch discussed in this work use a coplanar waveguide (CPW) transmission line, covered by a thin silicon nitrate patch as dielectric just under the membrane. The dielectric provides a capacitive path for the RF signal while avoiding short circuiting of the transmission line to ground. From an electrical view the capacitive shunted switch achieves switching by varying

Manuscript received April 4, 2013; revised May 29, 2013.

E. S. Shajahan is presently with the Department of Electronics and Communication Engineering, National Institute of Technology Karnataka, Mangalore, India.(e-mail: shajes2007@ gmail.com).

M. S. Bhat is with the Department of Electronics and Communication Engineering, National institute of Technology Karnataka, India (e-mail: msbhat_99@yahoo.com). capacitance in the ON and OFF position [2]. In the following sections a brief description of the design is presented. DC and RF characteristics of the proposed switch are analyzed for different beam geometry. Results obtained from simulation are presented using MATLAB.

\section{DESCRIPTION OF THE CAPACITIVE MEMS SWITCH}

A six arm capacitive coupled RF MEM switch is designed on a coplanar waveguide (CPW) with characteristic impedance $\left(\mathrm{Z}_{0}\right)$ of $50 \Omega$ and dimensions $(\mathrm{G} / \mathrm{W} / \mathrm{G})$ of $60 / 100 / 60$ (all in $\mu \mathrm{m}$ )[1]. The switch is designed over a silicon substrate of dimensions 500x500x500 ( $\mu \mathrm{m})$.Separate anchors are provided for the arms of the gold beam as shown in Fig 1 (a). Table I shows dimensions of the proposed switch. The actuation or pull-in voltage is analyzed by varying the physical dimensions of the beam, namely, length $\mathrm{L}$, width $\mathrm{w}$, beam thickness $\mathrm{T}$ and air gap $\mathrm{g}$.
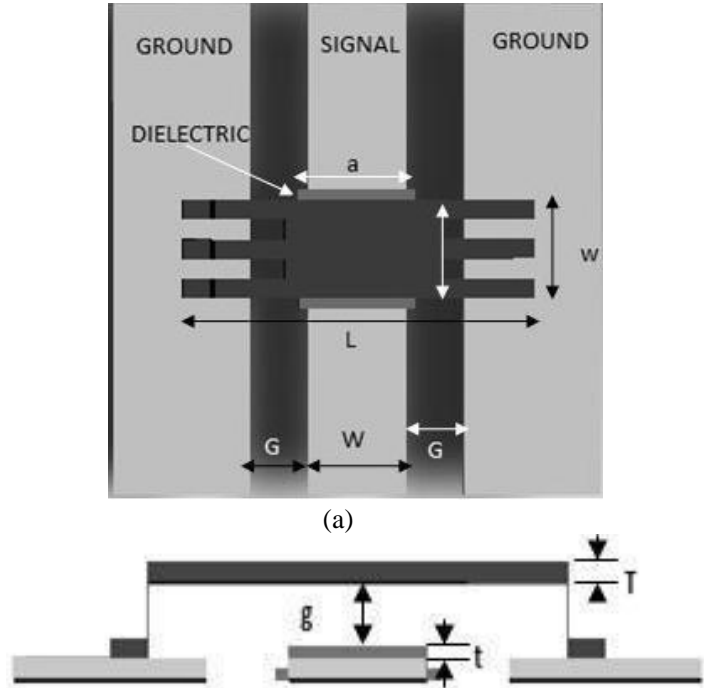

(b)

Fig. 1.Proposed Switch. (a) Top View (b) Side View

TABLE I: PARAMETERS AND DIMENSIONS OF THE SWITCH

\begin{tabular}{l|l}
\hline \multicolumn{1}{c|}{ Parameters } & \multicolumn{1}{c}{ Values } \\
\hline CPW dimensions $(\mu \mathrm{m}) \mathrm{G} / \mathrm{W} / \mathrm{G}$ & $60 / 100 / 60$ \\
Length of the membrane $\mathrm{L}(\mu \mathrm{m})$ & 300 \\
Width of the membrane $\mathrm{w}(\mu \mathrm{m})$ & 100 \\
Dimension of Dielectric $(\mu \mathrm{m})$ & $120^{*} 120$ \\
Dielectric constant of $\mathrm{Si}_{3} \mathrm{~N}_{4}\left(\varepsilon_{\mathrm{r}}\right)$ & 8.0 \\
Thickness of membrane, $\mathrm{T}(\mu \mathrm{m})$ & 1 \\
Thickness of Dielectric, $\mathrm{t}(\mu \mathrm{m})$ & 0.1 \\
Air gap, $\mathrm{g}(\mu \mathrm{m})$ & 3 \\
Relative dielectric constant of Si & 11.7 \\
\end{tabular}


Fig. 1(a) and (b) shows the top view and side view of the switch respectively. For the same dimensions, pull-in voltage is obtained by simulation for gold, aluminum, titanium and platinum. In RF MEM switches, since resistivity of the membrane directly impacts the RF performance (low RF loss), aluminum and gold are the preferred choice. In this design, gold is chosen for both CPW transmission line and beam.

\section{A. Operation of the Switch}

Electrostatic actuation is the widely used actuation mechanism in RF MEMS switches because of low power consumption and compact size, but high pull-in and low switching speed are the challenges. Although thermal and piezoelectric actuation requires less voltage to pull the beam down, they are not preferred over electrostatic method because of their complex fabrication. Electrostatic actuation overcomes the spring force to pull the membrane towards the $\mathrm{CPW}$ center conductor resulting in capacitive loading of the transmission line. The pull-in voltage is given by [2], [3]

$$
V_{P}=\sqrt{\frac{8 K g^{3}}{27 \varepsilon_{0} W w}}
$$

$K$ is spring constant of the membrane, $\mathrm{g}$ is the air gap, $\varepsilon_{0}$ is the permittivity of free space, and $\mathrm{W}$ is the width of the center conductor and $\mathrm{w}$ is the width of the beam.

\section{B. On and off Capacitance}

In the unactuated state (switch $\mathrm{ON}$ ), RF signal travels through the CPW transmission line unhindered by the low capacitance ( a few femto farads). The ON state capacitance is given by [3], [4]

$$
C_{O N}=\left(\frac{\varepsilon_{0} W w}{g+\frac{t}{\varepsilon_{r}}}\right)+C_{f}
$$

where $C_{f}$ is the fringing field capacitance and $\varepsilon_{\mathrm{r}}$ is relative dielectric constant. In the actuated state (switch OFF), the electrostatic force pulls the membrane down, resulting in capacitive loading of the $\mathrm{CPW}$ transmission line. The Off state capacitance is given by [4]

$$
C_{\text {OFF }}=\frac{\varepsilon_{0} \varepsilon_{r} W w}{t}
$$

\section{DC PERFORMANCE ANALYSIS}

\section{A. Impact of Membrane Materials on Pull-in Voltage}

Fig. 2 illustrates the dependence of the membrane spring constant on Young's modulus and Poisson's ratio and thus on actuation voltage (observed from simulation) of the switch in Fig. 1. Table II shows the properties of the materials used in this study. Being materials of lower Young's modulus, Aluminum $\left(7.0 \times 10^{10} \mathrm{~N} / \mathrm{m}^{2}\right)$ and Gold $\left(8.0 \times 10^{10} \mathrm{~N} / \mathrm{m}^{2}\right)$ have good ductile and elongation properties.

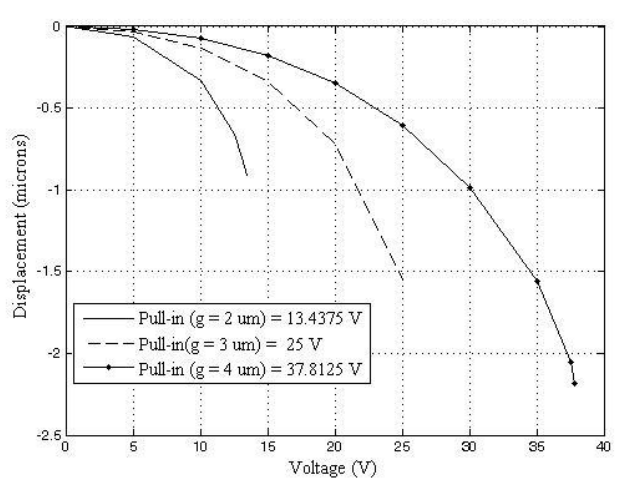

Fig. 2. Pull-in voltage for different materials

Beam is the key element of the switch. Its geometry, size, thickness, material and gap to CPW transmission line determine the actuation voltage and signal transmission efficiency.

High conductivity metals such as gold and aluminum have low melting point and therefore have low thermal stability and show plastic deformation of the membranes at relatively low temperature $\left(<200^{\circ} \mathrm{C}\right)$. High melting point metals such as Platinum show plastic deformation only at high temperatures which makes them attractive for use as membrane material in RF MEM switches. [5]

\section{B. Impact of Beam Length (L) Variations}

It is observed from simulation and shown in Fig.3 that spring constant and thus pull-in voltage $\left(V_{P}\right)$ has significant inverse relation with beam length $(\mathrm{L})$. The pull-in voltage is found to be in excess of $80 \mathrm{~V}$ for beam length of around 200 $\mu \mathrm{m}$.

\section{TABLE II: MATERIAL PROPERTIES}

\begin{tabular}{l|cc}
\hline \multicolumn{1}{c|}{ Material } & $\begin{array}{c}\text { Young's Modulus } \\
(\mathrm{GPa})\end{array}$ & Poisson's ratio \\
\hline Aluminium & 70 & 0.345 \\
Gold & 80 & 0.44 \\
Titanium & 120 & 0.321 \\
Platinum & 145 & 0.377 \\
\hline
\end{tabular}

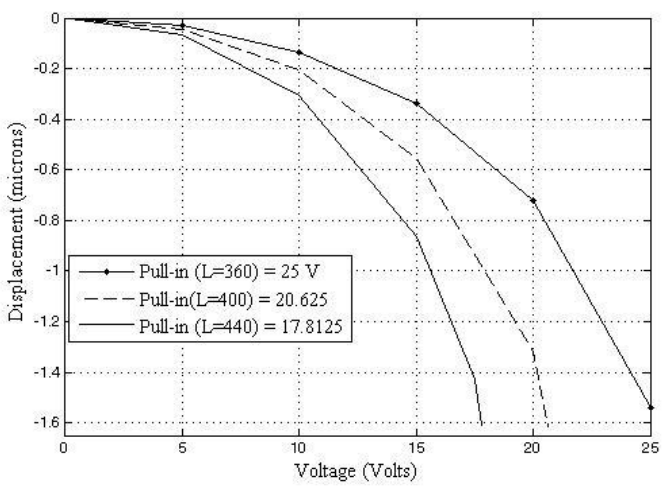

Fig. 3. Pull - in for various beam lengths

\section{Impact of Variations in Width (w) of the Beam}

Fig. 4 shows the inverse dependence of pull-in voltage on the actuation area $\left(\mathrm{W}^{*} \mathrm{~W}\right)$, where $\mathrm{W}$ is the width of the signal line and $w$ is the width of the switch beam. Actuation voltage is not much affected by the width. 


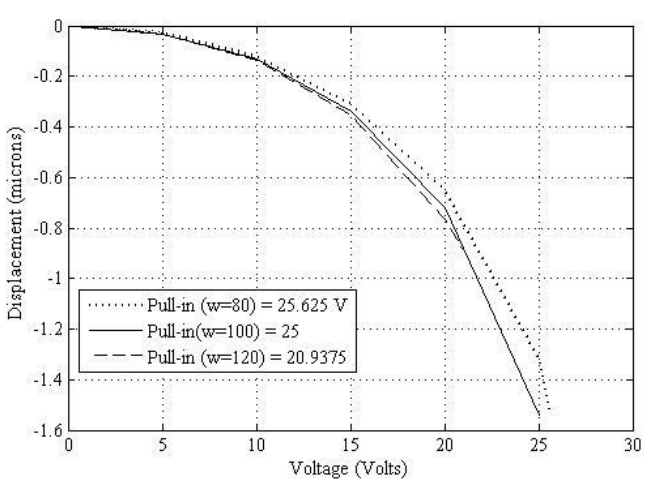

Fig. 4. Effect of beam width on Pull-in voltage

\section{Impact of Beam Thickness $(T)$}

Spring constant $(\mathrm{K})$ of the beam has strong direct relation with thickness. Large variations in pull-in voltage are shown in Fig. 5.

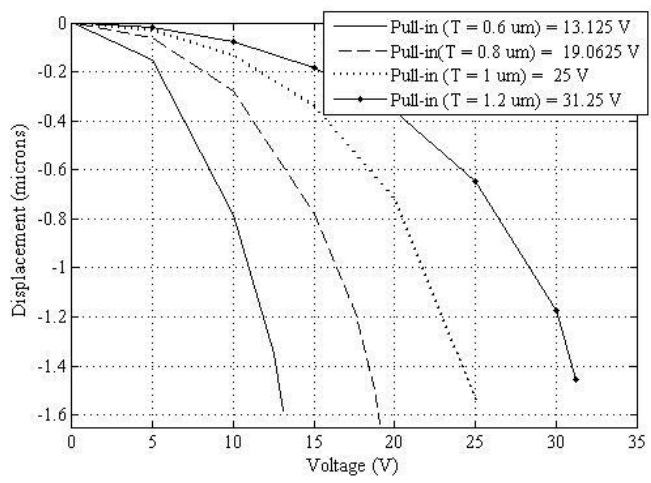

Fig. 5. Pull-in for beam thickness variations

\section{E. Impact of Air Gap ( $g)$}

Fig. 6 illustrates the variations in pull-in voltage due to air gap (g). Air gap below $2 \mu \mathrm{m}$ significantly impacts the reliability of the switch due to stiction.

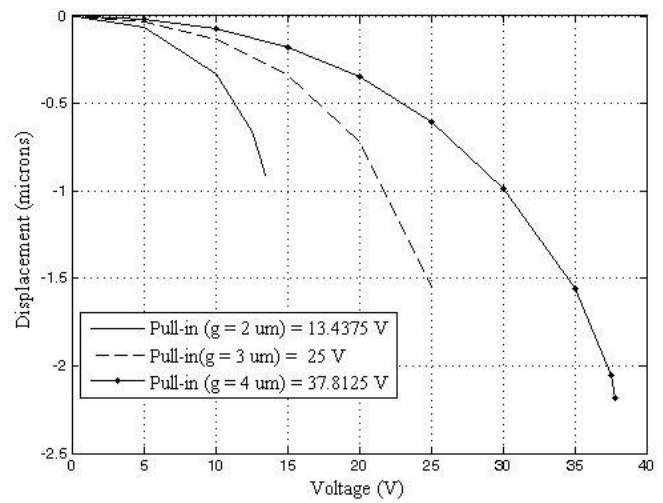

Fig. 6. Pull in for variations in air gap

\section{S - PARAMETER ANALYSIS}

The operating performance of RF switches is estimated by insertion loss, isolation and return loss. The proposed switch design is simulated in Ansoft HFSS for frequencies in the range of $1-40 \mathrm{GHz}$ in both up and down states of the membrane.

\section{A. Effect of Membrane Width (w) on S-Parameters}

Fig. 7- 10 illustrates the effect of (w) on $\mathrm{S}$ - parameters. It is observed from simulation shown in Fig. 7 that insertion loss increases with membrane width. In the range of 20-40 $\mathrm{GHz}$, for a membrane width of $60 \mu \mathrm{m}$, HFSS simulation shows a transmission loss of only $(0.03-0.2) \mathrm{dB}$ whereas this loss is $(0.05-0.56) \mathrm{dB}$ with $120 \mu \mathrm{m}$ membrane. This is due to the increase in $\mathrm{C}_{\mathrm{ON}}$ as in (2).

At the same time, increase in membrane width results in increased reflection making ON state return loss worse as shown in Fig. 8. From Fig. 9, it is seen that isolation characteristics exhibits series LC resonance behavior and is getting steeper and deeper with increase in width of the beam. This is due to the increase in capacitance and this also explains the change in resonance frequency of the switch.

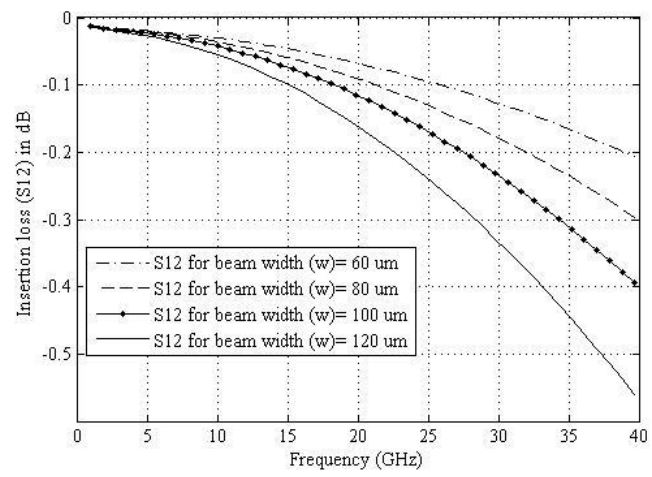

Fig. 7. Insertion Loss (S21)

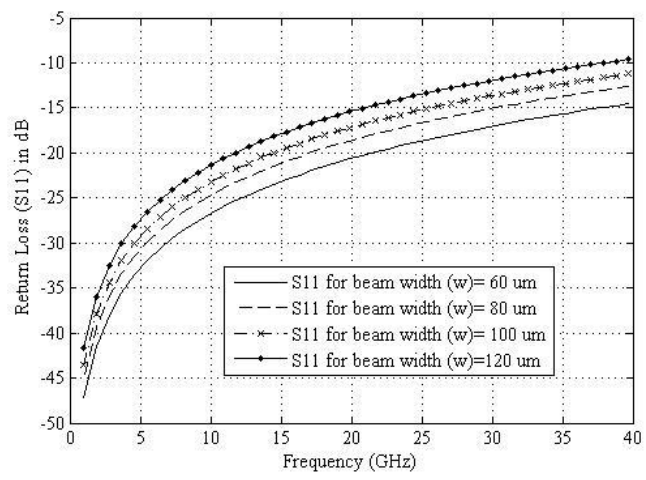

Fig. 8. ON State Return Loss (S11)

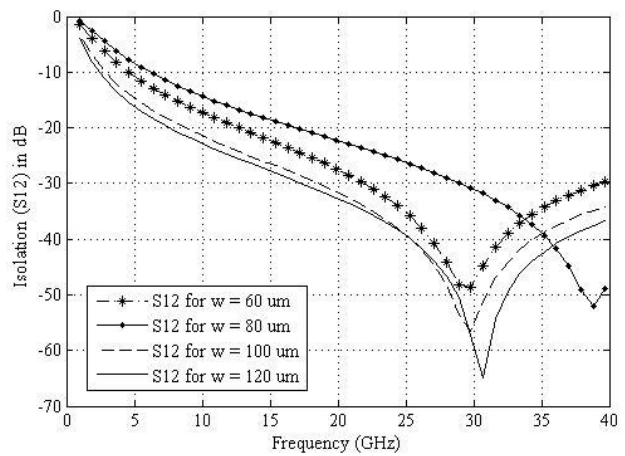

Fig. 9. Effect of beam width on isolation (S21)

Fig. 10 shows return loss in OFF state with almost unity reflection coefficient at higher frequencies.

\section{B. Effect of Dielectric Thickness $(t)$}

As shown in Fig. 11 transmission loss is not affected much 
by increased dielectric thickness. Transmission loss includes dielectric loss, conductor loss and reflection due to impedance mismatch.

As illustrated in Fig. 12, isolation is better than $30 \mathrm{~dB}$ for a dielectric thickness of $0.1 \mu \mathrm{m}$ and becomes worse as thickness increases to $0.6 \mu \mathrm{m}$. Increased thickness results in reduced $\mathrm{C}_{\mathrm{OFF}}$ as given in (3) thereby making capacitive loading of the transmission line less effective.

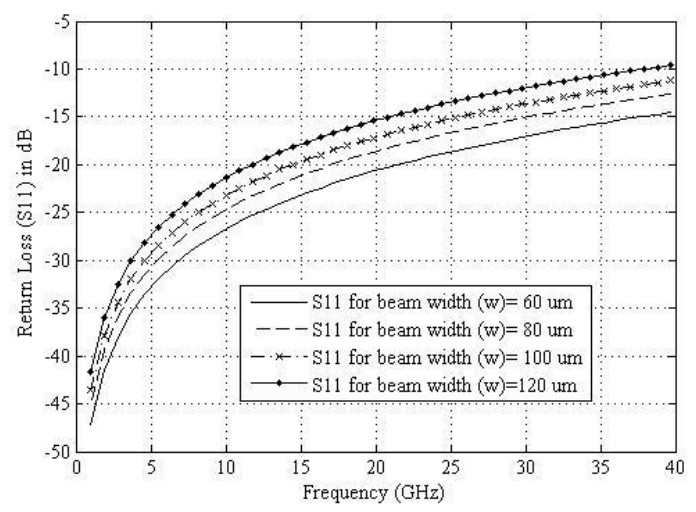

Fig. 10. OFF State Return Loss (S11)

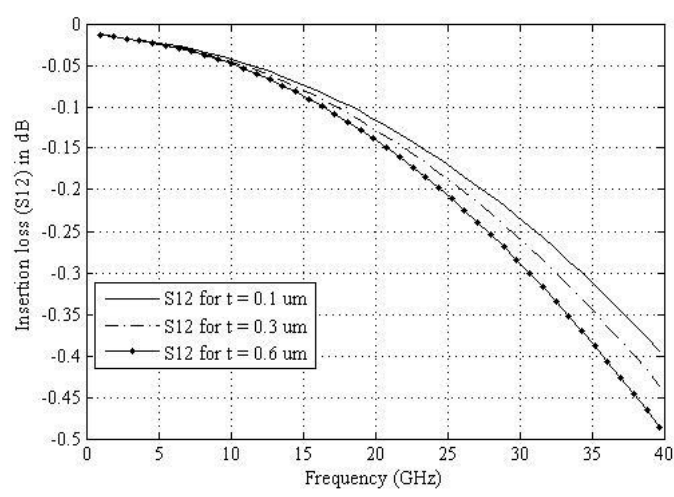

Fig. 11. Effect of beam thickness (t) on insertion Loss

Series resonance of the switch is very beneficial to isolation performance of the shunt switch. High isolation can be achieved around the LC resonance of the switch [3]. For a dielectric thickness of 0.1 microns, isolation is observed to be $56 \mathrm{~dB}$ at resonant frequency of $30 \mathrm{GHz}$. As dielectric thickness $(\mathrm{t})$ increases, capacitance decreases and resonance of the switch and thus the isolation band gets shifted to millimeter wave band of frequencies (40-100 GHz).

OFF state return loss is not at all affected by variations in dielectric thickness as shown in Fig. 13.

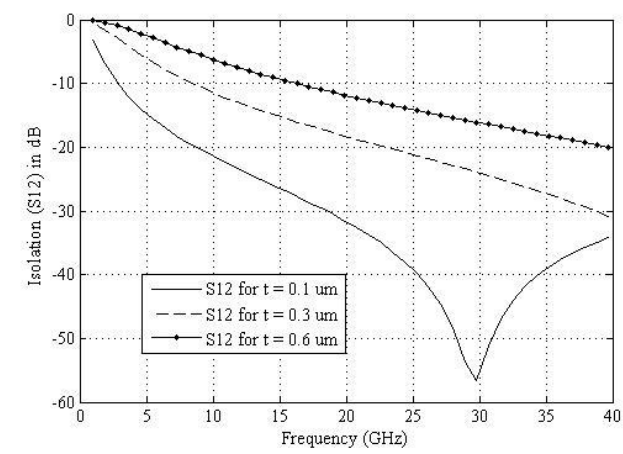

Fig. 12. Effect of dielectric thickness on isolation (S21)

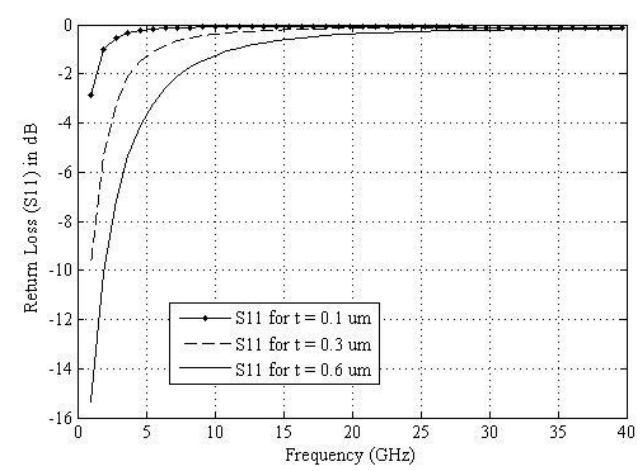

Fig. 13. OFF state Return Loss for dielectric thickness

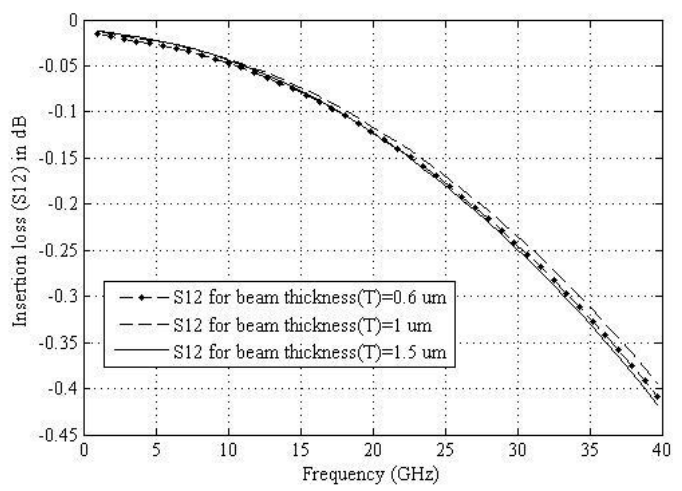

Fig. 14. Insertion Loss for varying beam thickness

\section{Effect of Beam Thickness (T)}

As can be seen in Fig. 14, beam thickness has very little impact on S-parameters in both ON and OFF states. The skin depth reduces inversely with square root of frequency and translates into a resistance that increases with square root of frequency. Thus conductor losses increase with frequency. For Au beam, the skin depth is $0.73 \mu \mathrm{m}$ at $10 \mathrm{GHz}$ and 0.56 $\mu \mathrm{m}$ at $20 \mathrm{GHz}$. This explains the increase in insertion loss with frequency.

\section{CONCLUSION}

A capacitive shunt RF MEM switch for applications in the range of $10-40 \mathrm{GHz}$ is presented. Simulation results show that the switch with aluminum beam has the lowest actuation voltage and platinum the highest for identical beam geometry. Aluminum and gold with low melting point has poor thermal performance compared to high melting point metals such as platinum. Yet they are preferred because of their high conductivity and lower Young's modulus. It is seen that air gap also has strong influence on actuation voltage. But small air gap may cause stiction due to adhesive forces or dielectric charging, or it may also result in hot switching.

S - Parameters of the proposed switch are studied by varying beam geometry. It is observed from simulation that beam width has significant impact on RF performance in $\mathrm{ON}$ and OFF states. It is also observed that increased dielectric thickness results in poor isolation. One way to improve isolation is to use dielectrics with high relative dielectric constant. Lower range of the dielectric thickness is limited by pin-hole problems and dielectric breakdown and upper range 
is limited by dielectric charging. Although beam thickness affects pull-in voltage, it has little impact on S-parameters. The results obtained in this work would help to refine and develop novel RF MEM switches for a broad range of applications.

\section{REFERENCES}

[1] G. M. Rebeiz, RF MEMS: Theory Design and Technology, $1^{\text {st }}$ ed Hoboken, NJ : John Wiley and Sons., 2003, ch. 2, pp. 45-47.

[2] Y. S. Hijazi, Y. A. Vlasov, and G. S. Larkins, "Design of a superconducting MEM Shunt switch for RF Applications," IEEE Trans. on Applied Superconductivity, vol. 13, pp. 696-699, June 2003

[3] J. B. Muldavin and G. M. Rebeiz, " High Isolation CPW RF MEMS Shunt Switches --Part 1: Modelling," IEEE Trans. on Microwave Theory and Techniques, vol. 48, no. 6, pp. 1045-52, June 2000.

[4] K. Chen, Y. Y. Dai, X. D. Zou, J. W. Zhang, "A Low Loss RF MEMS Switch with dielectric layer on the lower surface of the bridge," in Proc. $4^{\text {th }}$ IEEE International Conference on Nano/Micro Engineered and Molecular Systems, Shenzhen, 2009, pp. 152-155.

[5] P. Ekkels, X. Rottenburg, R. Puers, and H. A. C. Tilmans, "Evaluation of platinum as a structural thin film material for RF MEMS devices," $J$. Micromech. Microeng., vol. 19, no. 6, pp. 10-18, May 2009.

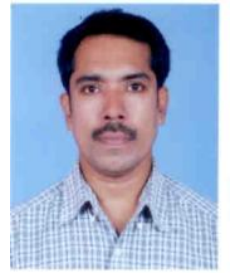

E. S. Shajahan has received his B. Tech degree in Electronics and Communication Engineering from the University of Kerala, India in 1994 and M. Tech degree in Digital systems and Communication Engineering from National Institute of Technology Calicut, Kerala, India in 2004. He is working as a faculty in the Department of Electronics and Communication Engineering, College of Engineering Trivandrum, Kerala, India. He is currently pursuing his Ph.D. in the Department of Electronics and Communication Engineering, National Institute of Technology Karnataka, Surathkal, India. His research interests include RF MEMS switches for reconfigurable RF micro systems.

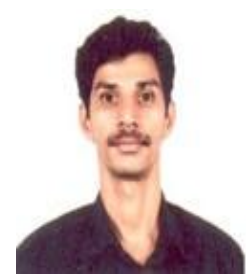

M. S. Bhat received his M.Sc. in Physics from Mangalore University, M.Tech from NITK Surthkal and Ph.D. from Indian Institute of Science, Bangalore in 1987, 1989 and 2007 respectively. He joined the Department of Electronics and Communication Engineering, NITK Surathkal as a faculty in 1989 and currently, he is a Professor in the Department. At NITK Surathkal, he was the coordinator of World Bank Sponsored project IMPACT in 2000-2002. Since 2007, he is the Co-coordinator of Special Manpower Development Project in VLSI, funded by Department of Information Technology, Govt. of India. Currently he is supervising 2 projects in the area of RF MEMS circuits funded by DIT and NPMASS, Govt. of India. His research interests include High Speed Interconnect Design, RF MEMS, Low Power Analog \& Mixed Signal Design and Image \& Signal Processing. 